The instrument is equally applicable to all sized heads, and forms its own unit of measurement for each, thus eliminating the errors caused by using standard measures for varying surfaces. It is compact, light, durable, and may be rendered aseptic by boiling. Messrs. Arnold and Sons, London, are the makers.

\section{LIST OF INDICES}

TO IMPORTANT REGIUNS OF THE BRAIN CORTEX.

Descrtption.

INDEX.

Motor Centres: External Aspect:

Inferior Estremity.......... $\frac{\mathrm{LK}}{8}$

Superior $\quad$, $\ldots \ldots \ldots \ldots \frac{\mathrm{K}}{6}$

Face $\ldots \ldots \ldots \ldots \ldots \ldots \ldots$

Lips and Tongue (Bruca's lobej (Left Side)

llead and Ejes ............ $\frac{1}{7}$ Mesia! Aspert :

Leg $\ldots \ldots \ldots \ldots \ldots \ldots \ldots \ldots \ldots \ldots$

Trunk $\ldots \ldots \ldots \ldots \ldots \ldots \ldots \ldots \ldots \ldots$

Arm $\ldots \ldots \ldots \ldots \ldots \ldots \ldots \ldots \ldots+\ldots \ldots$

Head $\ldots \ldots \ldots \ldots \ldots \ldots \ldots \ldots, \frac{H I}{13}$

Sensury lenties. Hearing $\ldots \ldots \ldots \ldots \ldots \ldots \ldots$.

Sight $\quad \ldots \ldots \ldots \ldots \ldots \ldots \ldots \frac{R}{6}$

Special Cincontutions . Frontal $\cdot$ Ascending ........ $\frac{1}{4} \odot{ }_{3}^{k}$

Superior ................

Middle .............

Inferior.............

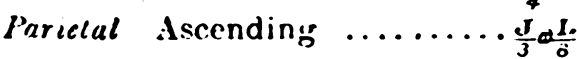

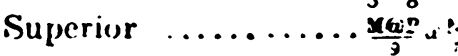

Supramarginat $\ldots \ldots$. MN

Angular $\ldots \ldots \ldots \ldots \frac{0}{5 x^{\prime}}$

Octipital $\cdot$ 1st ...............

Ind $\ldots \ldots \ldots \ldots \ldots$ s.

3rd ...........

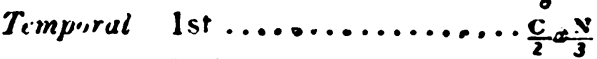

2nd $\ldots . . \ldots \ldots \ldots \ldots, \frac{1}{J_{a}}$

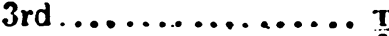

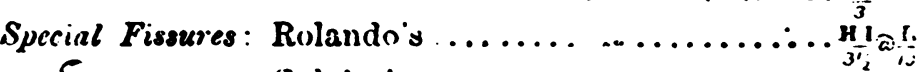

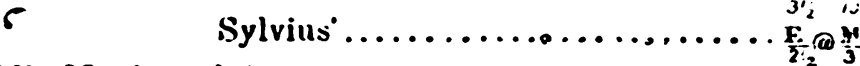

Middle Meningeal A rtery $\ldots \ldots \ldots \ldots \ldots \ldots \ldots \ldots \frac{\frac{2}{E}}{3}$

Cerebellum ............................ v v

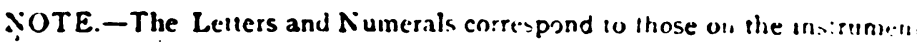

When two letters are placed thus-LK--it means a point hait way between them

When an index is given th: $:-\frac{1}{4} \rightarrow \frac{K}{9}-$ it means the poritivn; at these two points and that betwcen then, wien the this-

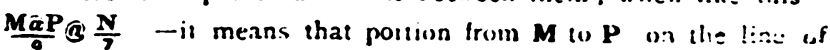
latude marked 9 . down to $\mathbf{N}$ on the line marke.li

\section{NOTES ON A SUCCESSFUL CASE OF} PYLOROPLASTY.

THOMAS OLIVER,
$\begin{gathered}\text { MY.D., F.R.C.P., Physician to the } \\ \text { Royal Infirmary, Newcastle- } \\ \text { on-Tyne. }\end{gathered}$

The following case seems to us to be of sufficient value to be recorded on account of the severe nature of the operation performed upon a patient rapidly dying from sheer starvation, and who, shortly after the shock and the immediate consequences of the operation were recovered from, gained strength and put on flesh at such a rapid rate as to render her hardly recognisable by her most intimate friends. To the medical officer of the convent, Dr. Ruddock of Newcastle, the writers gladly acknowledge their indebtedness, not only for his skilled assistance at the operation, but for permission to publish the notes of the case.

On November 2nd, 1896, one of us, Dr. Oliver, saw in consultation with Dr. liuddock, a nun, aged 25 , in one of the Roman Catholic convents of this city, a French Canadian by birth. She was extremely emaciated, pale, and so feeble that she could not sit up in bed. After having suffered from dyspeptic symptoms for several years, followed by marked declension of health, she was transferred from the West of England to Newcastle in the hope that our bracing atmosphere would act as the much needed restorative. Anorexia, gastralgia, and recurrent voniting were the symptoms which caused her to seek medical relief. Of late, debility, anæmia, and emaciation had made rapid strides. At first the vomiting only occurred after meals and gave relief to pain, but latterly it had been occurring at irregular and rather lengthened intervals - three to four days - when large quantities of liquid would be ejected, frequently coffee ground in character, occasionally of an ashy-grey colour, and usually with a most offensive odour. Previous to February, 1896, menstruation had been irregular, but since that date it had been in complete abeyance. The bowels were constipated, the urine normal. When seen by Dr. Oliver, the patient was too ill to be subjected to a prolonged examination. The temperature was normal, pulse 78, small and flickering. The face was pale, and expressive of lengthened suffering; tongue moist and clean. The heart and lungs were healthy. Abdomen was slightly protuberant, especially in its lower half anteriorly. Liver dulness was normal. Stomach : the area over which a normal resonant note could be heard was increased, whilst occupying the lower half of the abdomen, and extending almost to the suprapubic line was a cystic swelling, dull on percussion, the dulness varying with change of position of the patient. Fluctuation was well marked. On auscultation, and even without it, a splashing sound could be easily heard. Nothing was felt at the pylorus. Dilated stomach was diagnosed, and as the patient was extremely ill a fresh attempt was made by means of strong beef tea enemata, containing a few drops of laudanum, administered four times a day, to get her into a better condition for the surgical treatment which seemed to us the only chance left her. As the enemata were retained she soon began to gain in strength and vitality, but the improvement was only temporary. As consent had meanwhile been obtained for the surgical procedure, it was decided, after consultation with Mr. Page, ill as the patient was, and hopeless almost as was her condition, to perform without further delay_abdominal section.

Note hy Mr. Page.

On November 26th abdominal section was performed. Upon opening the abdomen in the middle line above the umbilicus, the stomach was found to be enormously dilated. The pylorus was thickened and fixed. Mikulicz's operation was performed. The stricture only permitted a pair of sinus forceps to pass through from the stomach to the duodenum. For some hours it was very doubtful as to whether the patient would rally; but gradually she did so, and made a rapid and most satisfactory recovery. Pyloroplasty for the treatment of non-malignant stenosis of the pylorus does not seem yet to occupy, in the estimation of British surgeons, the position it deserves. Gastroenterostomy still appears in this country to be the operation resorted to in many cases of simple stenosis and yet few surgeons, I am sure, who in their own practice contrast the results of the two operations will be nclined to adopt gastroenterostomy.

It has been said that " recurrence of the stricture is a physical impossibility" after this operation-a somewhat rash statement, perhaps. The operation has now been practised for some years, and I have certainly not heard of a recurrence. The man upon whom I operated in the year 1892 -the first case of pyloroplasty in Great Britain-remains well and is at his ordinary work, and I know of other cases in this neighbourhood where there has been no recurrence. The great danger arises from the operation being deferred too long. Two of my patients died from the direct effect of the operation within a few hours of its performance. 
The patient, when seen early in March by Dr. Oliver, seemed in perfect health. Although less than four months since the operation, she had gained upwards of $26 \mathrm{lbs}$. in weight.

\section{A CASE OF PARALYSis OF THE SIXTH NERVE FOLLOWED BY DIPLEGIA : RECOVERY. ${ }^{1}$}

By D. J. WOOD, M.B., C.M.Edin., Cape Town.

ON March 28th, I $896, G$. H. came to me complaining of double vision. Diplopia had come on gradually during two days, and he was unable to get about properly. There was convergent squint, absence of rotation outwards, and, when tested with lights, the cause was found to be pure right sixth nerve paralysis.

The history was found entirely negative. He was a healthy, well-built lad of 18 , singularly free from disease as a child and since. A year ago he had had a severe headache for two days consequent on exposure to the sun when fishing, but otherwise he had been well. His father was a sufferer from gout, perhaps also from rheumatism which had cansed distortion of several joints, especially those of the hands. Syphilis was inquired for in both father and son, and was denied, no doubt truthfully.

The diagnosis seemed fairly certain that it was a case of so.called rheumatic paralysis in a case of inherited gout. Iodide of potassium 30 grains daily and milk diet were prescribed.

I saw him next on April 3rd. The day after seeing me he noticed a feeling of numbness in the toes of the left foot, which increased until the leg fell " asleep." Next day it was worse, and the face and hand participated, and by April and there was left hemiplegia from the lower part of the face down and complete in quality.

The orbicularis palpebrarum and frontalis were normal in action : voluntary motions were abolished in the lower left side of the face, but an involuntary smile was fairly symmetrical. The knee reflex (left) was slightly increased; there was no aniesthesia, and I take it that the numbness alluded to was an expression of motor weakness, as sensation was perfect.

As on the first examination, the vision was normal (acuity and fields), the eyes were healthy, and the heart and arteries apparently sound.

The condition seemed now much more serious and to point to a lesion in the upper part of the pons on the right side pressing on the right sixth nerve in its course, and damaging the motor tract and facial fibres before decussation (to the left). Judging from the onset there seemed a chance that the damage was caused from below the pons, but there were no signs of a gross lesion, and repeated inquiries onl strengthened the negative history. Temperature was normal. After five days the arm, leg, and face began to grow stronger, and the improvement continued.

On April 15th fresh symptoms appeared, the hemiplegia was nearly gone, but there was some difficulty in speaking and swallowing. The left side of the palate drooped, and as it apparently did not properly close the upper part of the pharynx, the patient could not prevent his breath from escaping through the nose, and a pseudo-dyspncea resulted. The iodide was increased to 60 grains daily, and liq. hyd. perch. 3 ss added.

Next day the articulation was worse, and a paralysis appeared on the right side of the face, similar to that which had disappeared from the left side. The movements of the tongue were impaired in all directions, but specially forwards and to the right. There was still no anæsthesia, pain, sense of illness, nor any trace of optic neuritis. There was, however, some mental weakness of which the patient was aware he laughed continually when spoken to or looked at, and though conscious of the absurdity, could not control himself.

On April 19th the original hemiplegia had entirely gone, I Read at a moeting of the Cape Town Branch of the British Medical Association. but speech was so bad as to be scarcely intelligible, and the patient preferred to write. Consonants " $t$ " and " $d$ " were spoken "nee," " $k$ " and " $q$ " as if " $h$ " and "wh," labials " $m$ " and " $n$ " were imperfectly finished off, " $r$ " was produeed fairly well. Owing to the paralysis of the lips the mouth remained open, and fluids escaped from the right side during drinking. 'I'he voice also was rather low pitched and husky.

From this time general amelioration set in, in less than a week the face was largely under control, speech more intelligible, and the mouth kept shut.

On May 218t, eight weeks from the commencement, there remained only slight weakness of the right face, some huskiness of voice, and the sixth nerve paralysis which ushered in the condition. Unfortunately the larynx was not examined, but I am inclined to think there was some paresis or other abnormality present.

It will be at once evident thates.

ident that we have here an unusual and atypical form of disease. We may begin by excluding entirely the suggestion of hysteria as the cause. At no period did any of the symptoms afford any ground for such a diagnosis.

The case resembled an acute or subacute disturbance of motor nerve structures in or near the lower part of the brain. From ordinary bulbar paralysis we separate it by its greater acuteness, the higher nerve centres involved, and the recovery of the patient. Pseudo-bulbar paralysis is even more improbable.

Peripheral neuritis seems more likely, but the absence of any toxic cause, and the fewness of the nerves effected, do not warrant the supposition. To account for the right sixth nerve paralysis, followed by the left hemiplegia, one must practically admit the disease to be in the right side of the pons, where also one must look for the cause of the facial paralysis. The locality is further narrowed by the fact that the sixth nerve is probably damaged below the point of decussation (nucleus or below), while the facial fibres (for the left face) were involved before decussating, and this could only be if the lesion were in the upper part of the right side of the pons. The latter right facial paralysis would be accounted for by the disease spreading down the right side of the pons till it reached the right facial nucleus or nerve. Extension of the disease from the right sixth nucleus to the right seventh nucleus would be easy on account of their close relation.

The connection between the nerve cells supplying the lower facial muscles and the hypoglossal nucleus affords a possible explanation of the paralysis of the tensor palati from the close connection between the hypoglossal and accessory nuclei. The point may be noted that the only infranuclear lesion, that of the sixth nerve, remained long after the others had vanished. Paralysis of theright sixth nerve had not entirely disappeared before the end of July; and diplopia to the right side, slight in degree and due probably to contraction of internal rectus, still (September 8th, 1896) persists.

The nature of the disease is even more obscure than its locality. Syphilis and other infective diseases seem entirely excluded, but I am not so certain that with a rheumatic history, even in a heart apparently healthy, we can exclude the chance of an embolic lesion with subsequent degeneration of the nerve substance.

The nearest case seems one related by Gowers of an acute poliomyelitis of the pontine and medullary nuclei and nerves, but in our case there was no symptoms of inflammation.

\section{a CASE OF WANDERING GDEMa, PROBably OF SEPTIC ORIGIN.}

By E. W. G. MASTERMAN, F.R.C.S., Damascus.

The following case recently under my care in this city seems to me to present features of a sufficiently unusual kind to be worth recording.

J. T., a Jew, aged 8, was on December 3oth, 1896, suddenly seized with pain in the left leg. Shortly after cedema of the leg was noticed gradually ascending from the foot to the 